\title{
Application of the general perceived self-efficacy scale in cardiovascular rehabilitation
}

\section{Applicazione di una scala di percezione dell'auto-efficacia in riabilitazione cardiologica}

\author{
Anna Maria Zotti1, Gianluigi Balestroni1, Paola Cerutti1, Silvia Rossi Ferrario1, \\ Elisabetta Angelino2, Massimo Miglioretti3
}

\begin{abstract}
Heart failure, oxidative stress and allopurinol. Application of the general perceived self-efficacy scale in cardiovascular rehabilitation. A.M. Zotti, G. Balestroni, P. Cerutti, S. Rossi Ferrario, E. Angelino, M. Miglioretti.

Psychosocial support, education and self-management are important complements of rehabilitation programs. A central concept in self-management is self-efficacy, which refers to oneself confidence in reaching a desired goal. The General Perceived Self-Efficacy scale (GSE), developed to measure self-efficacy at the broadest level, could be useful in the rehabilitation setting, in order to assess patients' selfmanagement difficulties as well as to design specific interventions for specific diseases.

Aim of this work is to verify the GSE Italian version psychometric properties applied to the rehabilitation setting. Data were analyzed from 395 in-patients attending cardiac $(\mathbf{8 3 . 8 \%})$ and neurological $(\mathbf{1 6 . 2 \%})$ rehabilitation. Car-
\end{abstract}

\begin{abstract}
diac patients suffered from post-MI, CABG or heart-failure; all of the neurological patients suffered from amiotrophic lateral sclerosis (ALS). They were mostly males $(84.5 \%)$, and the mean age was 55.7 years. Principal component factor analysis confirmed that GSE has a monofactorial structure with internal consistency of $\mathbf{. 8 5}$. As in previous studies, a gender difference emerged. There was no difference in cardiac patients, on the basis of their specific disease, but they showed higher self-efficacy perception compared to ALS patients. The findings confirm that GSE is a valid measure of self-efficacy in settings characterised by different levels of functional abilities, as in cardiac and neurological rehabilitation.
\end{abstract}

Keywords: self-efficacy, scale validation, cardiovascular diseases, Amiotrophic Lateral Sclerosis.

Monaldi Arch Chest Dis 2007; 68: 178-183.

1 Salvatore Maugeri Foundation, Institute for Clinical Care and Research (IRCCS); Psychology Unit, Scientific Institute of Veruno (NO) Italy.

2 Salvatore Maugeri Foundation, Institute for Clinical Care and Research (IRCCS); Health Head Office, Casa di Cura Major, Torino Italy.

${ }^{3}$ ASL 3, "La Colletta" Hospital, Unit of Rehabilitative Cardiology, Arenzano (GE) Italy.

Corresponding author: Anna Maria Zotti; Servizio di Psicologia, Istituto Scientifico di Veruno; Via per Revislate 13, I-28010 Veruno (NO) Italy; E-mail address: azotti@fsm.it

\section{Introduction}

Since the first publications by Bandura [1, 2], the role of self-efficacy in the area of health, stress management and disease has received increasing attention as part of the transition from a biomedical to a biopsychosocial model.

Health-related self-efficacy perception refers to the subjective confidence to be capable of adopting a healthy life style and avoiding harmful behaviours [3].

A recent PubMed-MEDLINE search using "selfefficacy" as a key word, found that 6183 scientific papers were indexed between 1977 and May 2006 (Table 1). The self-efficacy construct is differently interpreted in the various papers and a large number of evaluation scales have been used, some of which very poor in terms of psychometric goodness [4-7]. In rehabilitation setting, patients affected by chronic diseases may have the capability to adjust continuously their coping through a flexible range of responses to life changes. This has led to the introduction of a new chronic disease paradigm based on patient empowerment and self-management education [8].

\begin{tabular}{|c|c|c|}
\hline Key words & $\begin{array}{l}\text { No. of } \\
\text { papers }\end{array}$ & Years \\
\hline Self-efficacy & 6183 & $1977-2006$ \\
\hline Self-efficacy and health & 3786 & 1978 \\
\hline Self-efficacy and rehabilitation & 1266 & 1978 \\
\hline Self-efficacy and chronic disease & 255 & 1985 \\
\hline $\begin{array}{l}\text { Self-efficacy and cardiac } \\
\text { rehabilitation }\end{array}$ & 83 & 1986 \\
\hline $\begin{array}{l}\text { Self-efficacy and myocardial } \\
\text { infarction (MI) }\end{array}$ & 53 & 1983 \\
\hline $\begin{array}{l}\text { Self-efficacy and Coronary Artery } \\
\text { Bypass Grafth (CABG) }\end{array}$ & 34 & 1988 \\
\hline Self-efficacy and heart failure (HF) & 40 & 1993 \\
\hline Self-efficacy and valve surgery (VS) & 4 & 1988 \\
\hline $\begin{array}{l}\text { Self-efficacy and heart } \\
\text { transplantation }(\mathbf{H T})\end{array}$ & 3 & 1998 \\
\hline $\begin{array}{l}\text { Self-efficacy and Amyotrophic } \\
\text { Lateral Sclerosis (ALS) }\end{array}$ & $\mathbf{0}$ & May 2006 \\
\hline
\end{tabular}


Thus, in rehabilitation setting self-efficacy is sometimes considered a predictive variable of outcomes, and sometimes as an outcome itself; it is often considered as a generalised construct that crosses disciplinary boundaries, as well as a construct related to specific behaviours and performances [9].

In chronic diseases such as diabetes, cancer, arthritis, COPD and others causing impaired mobility or pain, as well as in chronic diseases in the elderly, self-efficacy has mainly been studied as a predictor of adherence to treatment and of treatments capable of increasing the self-management of disease and daily coping tasks [10-19]. Bandura underlines the mediating role of self-efficacy in the relationship between biomedical factors and the quality of life of patients with chronic diseases: "functional limitations may be governed more by beliefs of capability than by the degree of actual physical impairment" [9, p. 300]. This is because a high level of perceived self-efficacy promotes the enactment of usefulness coping strategies that can decrease functional disability [19].

An analysis of the literature in the specific setting of cardiovascular rehabilitation shows that 19 of the 35 most recent papers examined consider the self-efficacy construct as a predictor of results, particularly in relation to physical exercise and adherence to the rehabilitation process; the other 16 consider it an outcome of the rehabilitation process itself.

Motor neuron disease or amyotrophic lateral sclerosis (ALS) is a useful paradigm for studying the responses of patients to the progressive and irreversible disability associated with many progressive neurological disorders [20], but it has not received any research attention in relation to the self-efficacy construct.

Although all of the general and specific research studies indicate that a low degree of self-efficacy (however evaluated) predicts or is an effect of poor disease management results, it is difficult to draw any definite conclusions concerning self-efficacy in the chronic disease rehabilitation setting mainly because of differences in the methodological and theoretical approaches of the studies themselves. On the other hand, in their overview of the construct, Maibach and Murphy [21] assert that there are no standard sets of self-efficacy measures that apply to all people in all situations: self-efficacy scales must be tailored to specific functioning domains.

As the rehabilitation process is multi-factorial and requires the formulation of differentiated interventions depending on the problems generated by diseases evolving to chronic or requiring adherence to complex treatments [22], it is necessary to identify the most appropriate theoretical model of reference and the most useful self-efficacy measure as a starting point for enhancing chronic disease management.

On the basis of these considerations, and in order to apply the self-efficacy construct to cardiovascular rehabilitation, we think it better to refer to the concept of generalised perceived self-efficacy developed by Jerusalem and Schwarzer [23], which provides a global reference for individual coping ability in a wide range of demanding situations. Measured by means of the General Perceived Self-Efficacy scale (GSE) [24], it has been found to be a better predictor of subjective well-being, self-reported illness and coping than concurrent measures of self-esteem or trait anxiety, or adherence to medical regimens [15, 25]. It seems to us that the GSE is a suitable instrument for the parsimonious measurement of self-efficacy that can not only be used by researchers and practitioners alike, but can also be applied in the context of population-based knowledge, especially given the time and fiscal constraints currently affecting most healthcare settings.

The aim of this study was therefore to verify the Italian version of the GSE [26, 27] in the context of cardiovascular and neurological rehabilitation, and to consider some still open questions, such as the relationship between self-efficacy and functional autonomy, by comparing cardiovascular patients with those affected by diseases involving progressive and irreversible disability.

\section{Method}

\section{Participants}

After having obtained their informed consent, we consecutively enrolled 395 subjects $(84,5 \%$ males) with a mean age of $55.7 \pm 9.6$ years (range 16-78), who had attended school/university for a mean $8.8 \pm 4$ years (range $5-18$ ): $74.6 \%$ were married; $48.4 \%$ were retired, $4.5 \%$ were housewives, and the rest had various working occupations.

The subjects were enrolled at the time of their first admission to a rehabilitation hospital in cardiac or neurological department. In particular $16.7 \%$ had experienced a recent myocardial infarction $(\leq 1$ month), $15.2 \%$ a first episode of heart failure, $26.6 \%$ had undergone recent coronary artery by-pass surgery $(\leq 10$ days), $19.5 \%$ had undergone a recent heart transplantation ( $\leq 1$ month) and $5.8 \%$ had undergone recent valve replacement surgery $(\leq 10$ days); in neurological setting $16.2 \%$ had amyotrophic lateral sclerosis ( $\leq 6$ months from diagnosis).

Table 2 shows their socio-demographic characteristics.

Table 2. - Socio-demographic characteristcs of the sample $(n=395)$

\begin{tabular}{|c|c|c|c|c|c|c|}
\hline \multirow{2}{*}{ Group } & \multicolumn{2}{|c|}{ Gender (n) } & \multicolumn{2}{|c|}{ Age (yrs) } & \multicolumn{2}{|c|}{ Education (yrs) } \\
\hline & $\mathbf{M}$ & $\mathbf{F}$ & mean & SD & mean & SD \\
\hline Myocardial infarction (MI) & 60 & 6 & 51.9 & 9.7 & 8.9 & 3.3 \\
\hline Heart failure $(\mathbf{H F})$ & 52 & 8 & 53.9 & 10.1 & 7.5 & 3.1 \\
\hline $\begin{array}{l}\text { Coronary artery by-pass graft } \\
\text { (CABG) }\end{array}$ & 93 & 12 & 57.1 & 7.6 & 8.7 & 3.7 \\
\hline Heart transplant $(\mathbf{H T})$ & 70 & 7 & 55.7 & 10.5 & 8.8 & 3.9 \\
\hline Valve surgery (VS) & 14 & 9 & 56.1 & 8.3 & 9.4 & 4.1 \\
\hline $\begin{array}{l}\text { Amyotrophic Lateral Sclerosis } \\
\text { (ALS) }\end{array}$ & 45 & 19 & 58.8 & 10.1 & 10.1 & 4.8 \\
\hline TOTAL SAMPLE & 334 & 61 & 54.9 & 10.1 & 9.5 & 4.1 \\
\hline
\end{tabular}




\section{Instrument}

We used the Italian version of the General Perceived Self-Efficacy scale (GSE), which consists of 10 items assessing the strength of an individual's beliefs in his/her ability to respond to and control environmental demands and challenges [26, 27]. The ten items have been adapted into 28 languages by bilingual native speakers on the basis of the German and English versions. The GSE has been used in a large number of research projects, in which it typically yielded internal alpha consistencies of between .75 and .91 . The scale is not only parsimonious and reliable, but has also been shown to have convergent and discriminant validity. The total 10 -item score theoretically ranges from 10 to 40 because of the 1 4 response format $[26,27]$.

\section{Statistical analysis}

The scale characteristics were studied by means of principal component factor analysis and the scree test. Item characteristics, item mean values, item/total correlations and Cronbach's alpha internal consistency were also evaluated. Student's t test for independent samples, ANOVA and Bonferroni's posthoc test were used to evaluate the socio-demographic and disease grouping effects on the self-efficacy score.

\section{Results}

The scree test and principal factor component analysis of the sample as a whole showed that the GSE has monofactorial structure (one-factor solution) with the first einge value being clearly higher than the others, and the second falling below unity (4.36, 0.87 and 0.80). Item 5 ("Thanks to my resourcefulness, I know how to handle unforeseen situations"; Italian version "Grazie alle mie risorse, so come gestire situazioni impreviste") has discriminative power (the highest factor loading).

The correlations between item mean values and the corrected total score are given in Table 3. All of the coefficients were satisfactory except that of item 2 ("If someone opposes me, I can find means and ways to get what I want"; Italian version "Se qualcuno mi contrasta, posso trovare il modo o il sistema di ottenere ciò che voglio"), but eliminating this item would not lead to any overall improvement: the internal consistency of Cronbach's alpha would change from .850 to .853 .

Table 4 shows the statistics of distribution of the self-efficacy scores in the sample as a whole. There are significant differences between men and women, with the latter having the lowest scores $(t=4.05$; $\mathrm{p}=.000)$. The number of years of education $(\leq 5,6-8$, 9-13 and $>13$ corresponding to the Italian Education system) had no effect on the self-efficacy scores ( $\mathrm{F}=$ $1.647 ; \mathrm{p}=\mathrm{ns})$. Grouping by age $(\leq 49,50-56,57-62$
Table 3. - Mean values of GSE items and their correlations with the total score

\begin{tabular}{cccc}
\hline Item & Mean & SD & Correlation \\
\hline 1 & 3.14 & 0.71 & 0.58 \\
\hline 2 & 2.68 & 0.86 & 0.38 \\
\hline 3 & 2.94 & 0.82 & 0.49 \\
\hline 4 & 3.05 & 0.77 & 0.62 \\
\hline 5 & 3.02 & 0.78 & 0.66 \\
\hline 6 & 3.33 & 0.61 & 0.64 \\
\hline 7 & 2.87 & 0.83 & 0.46 \\
\hline 8 & 2.97 & 0.74 & 0.56 \\
\hline 9 & 3.20 & 0.65 & 0.56 \\
\hline 10 & 2.85 & 0.84 & 0.62 \\
\hline & Cronbach's alpha .85 & \\
\hline
\end{tabular}

and $\geq 63$ years) did not affect the GSE score $(\mathrm{F}=.8 \overline{3} 5 ; \mathrm{p}=\mathrm{ns})$, nor did grouping by marital status (married vs single $\mathrm{t}=-1.610 ; \mathrm{p}=\mathrm{ns}$ ). Comparison of the retired $(54.6 \%)$ and still working subjects $(40.2 \%)$ revealed a significant difference of $p=.005$ $(\mathrm{t}=-2.802)$, with self-efficacy scores of respectively $29.5 \pm 5$ and $31 \pm 4.6$.

When the GSE scores were considered by disease groups, and gender (Table 5), only the group of ALS patients explains the between-group differences: Bonferroni's post-hoc test showed that they had GSE scores that were significantly lower than the patients who had undergone heart transplantation or by-pass surgery, and those who had suffered a myocardial infarction or a first episode of heart failure. There were no differences among the patients with heart disease related to their specific condition.

\section{Discussion}

The use of the GSE proved to be satisfactory in the highly specific setting of rehabilitation. Factorial analysis confirmed that the scale is homogeneous and unidimensional.

Factor loading, the correlations between item and total scores, and internal consistency could be considered satisfactory and were similar to those found in other European countries. As in the case of the validation of the GSE in the other languages, item 5 proved to be the one with the highest loading factor and, as in the case of the Greek and Spanish validation samples, item 2 proved to be the weakest $[26,27]$.

Table 4. - GSE score: mean value, SD, and statistic of the sample

\begin{tabular}{lccccccc}
\hline & Mean & SD & Range & Mode & Median & Skewness & Kurtosis \\
\hline Total sample (n 395) & 0.1 & 5.01 & $13-40$ & 30 & 30 & -0.38 & 0.40 \\
\hline
\end{tabular}


Table 5. - GSE score: mean values, SDs, and between-group disease comparisons by gender

\begin{tabular}{cccccccccccccc}
\hline & \multicolumn{2}{c}{ MI } & \multicolumn{2}{c}{ H F } & \multicolumn{2}{c}{ CABG } & \multicolumn{2}{c}{ H T } & \multicolumn{2}{c}{ VS } & \multicolumn{2}{c}{ ALS } \\
\hline & M & F & M & F & M & F & M & F & M & F & M & F \\
\hline Mean & 30.8 & 31.2 & 30.9 & 24.6 & 31.2 & 27.9 & 30.9 & 28.3 & 30 & 29 & 27.9 & 26.7 \\
\hline SD & 3.8 & 2.1 & 4.8 & 7.6 & 4.6 & 3.8 & 5.2 & 4.9 & 4.7 & 5.2 & 5.2 & 6 \\
\hline
\end{tabular}

Disease groups: $F=2.603 ; p=.02$

Gender: $F=10.006 ; p=.002$

Disease Groups by Gender: $F=1.612$; $p=n s$

Bonferroni's post hoc test

\begin{tabular}{cccccc}
\hline ALS vs & -3.32 & -2.57 & $-3,27$ & -3.13 & -2.08 \\
\hline $\mathbf{p}$ & .002 & .04 & .000 & .002 & n.s \\
\hline
\end{tabular}

Our results also confirmed the effects due to gender, with females having lower self-efficacy scores than males [26, 27]. There were no age-related differences in the scores, whereas McConnell et al. [28] found that infarction and CABG patients aged 50-69 years had higher self-efficacy scores than those aged 70-89 years.

Education does not seem to influence the self-efficacy construct, thus confirming that it relates to the objective reality of individual behaviours rather than to socio-cultural learning [26, 27].

A greater perception of self-efficacy discriminates retired from working patients, probably because younger people have other kind of expectations in their daily life and need much time to verify their feasibility. It was previously reported that the level of self-efficacy affects the resumption of working activities by patients discharged after PTCA [29] and those discharged after heart transplantation [30].

Analysis of the scores by disease groups revealed no differences between the cardiac patients belonging to different disease conditions. This finding confirms what was said by Barlow et al. [31]: the scale is designed to measure perceived self efficacy believes across a wide range of demanding situations and assess a unitary concept. Although $\mathrm{MI}$ and $\mathrm{CABG}$ are acute events, and heart failure is a chronic disease, the impact of these different conditions is apparent for an extended period of time, and they frequently share a substantial overlap in terms of organic and psychological symptoms (i.e. chest pain, dyspnea, dizziness, palpitations, exercise intolerance, anxiety, depression, fatigue and functional impairment in general activities). However, although different disease conditions may share common symptoms, pathophysiological characteristics and treatment goals, specific rehabilitation guidelines have been developed separately for the individual conditions and typically separate acute treatments from chronic management and secondary prevention [32]. Our data indicate that, in the field of cardiovascular rehabilitation, the self-efficacy perception crosses the disease conditions.
The degree of self-efficacy score of cardiac patients is clearly different from that of ALS patients. It seems that these differences are due to the awareness of being able to manage the disease or the perception of functional ability, because the patients who have found a surgical solution or who have the possibility of undergoing future surgery (such as infarcted patients) have a higher degree of self-efficacy than those who have no solution against disease progression. ALS patients have no solutions for controlling disease progression other than adhering to and accepting the use of some assistive devices (ADs), such as aids for mobility and language, and percutaneous gastrostomy (PEG) and/or ventilation therapy to relieve the most critical phases of the disease.

Our findings show that a generalized self-efficacy scale as GSE, instead of specific domains self-efficacy scale can be used to understand coping processes along different post-acute and chronic conditions. GSE may also be useful to select those patients who may be helped by counselling or cognitive behaviour therapy along the disease progression as ALS patients: Roelands et al. [33] have found that self-efficacy is related to a greater predisposition to accept and use ADs in elderly patients with problems of self-care and mobility.

Focusing on self-efficacy perceptions may be of particular significance in the task of long-term maintenance, which is often required in the successful management of chronic disease and may significantly influence the quality of life among patients with chronic illness [34].

Assessing which patients have low self-efficacy, and identifying those who might be less likely to perform self-management behaviors as a result, is likely to prove especially helpful in modifying health behaviors among the chronically ill.

\section{Conclusion}

An important aim of evidence-based healthcare is essentially that of improving the quality of interventions by means of close collaboration between researchers and clinicians in order to optimise costs 
and reduce the extreme variability of interventions for similar health conditions. The quality of the instruments available for the routine evaluation of health services will determine our ability to document the impact of rehabilitation programmes and evaluate further refinements within the context of an increasingly constrained and accountable health financing system [35].

It has been estimated that approximately $68 \%$ of all healthcare cost are associated with chronic illness and disability: given the apparent potential of psychosocial interventions in cardiac rehabilitation [36], patient screening and selective assignment or referral for psychological disease management seems to be more cost-efficient than giving all patients affected by a specific disease the same amount and type of care $[37,38]$. In this perspective, the General Perceived Self-Efficacy scale is easy to use and has good psychometric properties. It is also capable of discriminating impairment and, as it is not disease-specific, may also provide a foundation for better understanding the relationship between self-efficacy and successful outcomes.

\section{Riassunto}

Supporto psicologico ed educazionale ed autocontrollo sono importanti componenti dei programmi riabilitativi. Un concetto centrale nellauto-controllo è l'auto-efficacia, vale a dire la fiducia che ciascuno ripone nel raggiungere un determinato obiettivo. La General Perceived Self-Efficacy scale (GSE) può essere utile nel setting riabilitativo, per valutare le difficoltà del paziente nell'affrontare difficoltà ed anche per disegnare specifici interventi.

Scopo di questo lavoro è quello di verificare la applicabilità della versione italiana della GSE nel setting riabilitativo. Sono stati analizzati I dati di 395 pazienti nell'ambito di riabilitazione cardiaca (83.8\%) o neurologica (16.2\%), prevalentemente maschi (84.5\%), con età media 55.7 anni. L'analisi delle varie componenti ha confermato che la GSE ha una struttura monofattoriale con una consistenza interna di .85. Come in precedenti studi, vi era una differenza di genere. Non vi erano differenze a seconda del tipo di cardiopatia, ma i cardiopatici esibivano una migliore percezione dell'auto-efficacia rispetto ai pazienti neurologici. Il lavoro conferma che la GSE è un valido strumento per misurare la auto-efficacia in setting con differenti livelli di capacità funzionali, come in riabilitazione cardiologica o neurologica.

\section{References}

1. Bandura A. Self-efficacy: toward a unifying theory of behavioural change. Psychol Rev 1977; 84: 191-215.

2. Bandura A, Adams NE, Beyer J. Cognitive processes mediating behavioural change. J Pers Soc Psychol 1977; 35: 125-139.

3. Schwarzer R, Fuchs R. Changing risk behaviors and adopting health behaviors: The role of self-efficacy beliefs. In: Bandura A, eds Self-efficacy in changing societies. New York, Cambridge University Press, 1995: 259-288.
4. Conner M, Norman P. The role of social cognition in health behaviours. In: Conner M, Norman P, eds Predicting Health Behaviour. Buckingham, Open University Press, 1995: 1-22.

5. Haidt J, Rodin J. Control and efficacy as interdisciplinary bridges. Review of General Psychology 1999; 3: 317-337.

6. Clark NM, Dodge JA. Exploring self-efficacy as a predictor of disease management. Health Ed Behav 1999; 26 (1): 72-89.

7. Armitage CJ, Conner M. Social cognition models and health behaviour: a structured review. Psychology and Health 2000; 15: 173-189.

8. Bodenheimer T, Wagner E, Grumbach K. Improving primary care for patients with chronic illness. JAMA 2002; 288: 1775-1779.

9. Bandura A. Self-efficacy: The Exercise of Control. New York, Freeman, 1997: 300.

10. Bandura A. Exercise of agency in personal and social change. In: Sanavio E, ed Behavior and Cognitive Therapy Today. Oxford, Pergamon Elsevier Science, 1998: 1-29.

11. Lorig KR, Ritter P, Stewart AL, et al. Chronic disease self-management program: 2-year health status and health care utilization outcomes. Med Care 2001; 39 (11): 1217-23.

12. Lorig KR, Sobel DS, Laurent D, et al. Effect of a selfmanagement program on patients with chronic disease. Eff Clin Pract 2001; 4 (6): 256-262.

13. Lev E, Paul D, Owen SV. Age, self-efficacy, and change in patients' adjustment to cancer. Cancer Pract 1999; 7 (4):170-76.

14. Hewlett S, Cockshott Z, Kirwan J, et al. Development and validation of a self-efficacy scale for use in British patients with rheumatoid arthritis (RASE). Rheumatology 2001; 40: 1221-1230.

15. Scherer YK, Schmieder LE. The effect of a pulmonary rehabilitation program on self-efficacy, perception of dyspnea, and physical endurance. Heart Lung 1997; 26 (1): $15-22$.

16. Arnstein P, Caudill M, Mandle CL, et al. Self-efficacy as a mediator of the relationship between pain intensity, disability and depression in chronic pain patients. Pain 1999; 80 (3): 483-91.

17. Resnik B. Geriatric rehabilitation: the influence of efficacy beliefs and motivation. Rehabil Nurs 2002; 27 (4): 152-159.

18. Senecal C, Nouwen A, White D. Motivation and dietary self-care in adults with diabetes: are self-efficacy and autonomous self-regulation complementary or competing? Health Psychology 2000; 19 (5): 452-457.

19. Kohler CL, Fish L, Greene PG. The relationship of perceived self-efficacy to quality of life in chronic obstructive pulmonary disease. Health Psychology 2002; 21: 610-614

20. Young CA, Tedman BM, Williams IR. Disease progression and perceptions of health in patients with motoneurone disease. J Neurol Sci 1995; 129 suppl: 50-53.

21. Maibach EW, Murphy DA. Self-efficacy in health promotion research and practice: conceptualisation and measurement. Health Education Research 1995; 10: 37-50.

22. Myers LB, Midence K. eds Adherence to treatment in medical conditions. Harwood, Academic Publishers, 1998.

23. Jerusalem M, Schwarzer R. Self-efficacy as a resource factor in stress appraisal processes. In: Schwarzer R. ed Self-efficacy: Throught Control of Action. Washington DC, Emisphere, 1992: 195-213.

24. Schwarzer R, Jerusalem M. Generalized Self-efficacy Scale. In: Weinman J, Wright S, Johnston M. eds Measures in health psychology: a user's portfolio. Causal and control beliefs. Windsor, UK: Nfer-Nelson, 1995: 35-37.

25. Schroder K, Schwarzer R, Kornert Z. Coping as a mediator in recovery from heart surgery: a longitudinal study. Psychology \& Health 1998; 13 (1): 83-97. 
26. Sholz U, Dona BG, Sud S, Schwarzer R. Is general selfefficacy a Universal construct? Psychometric finding from 25 Countries. European Journal Psychological Assessment 2002; 18 (3): 242-251.

27. Schwarzer R. Measurement of perceived self-efficacy. Psychometric scales for cross-cultural research. Berlin, Frie Universitat Berlin, 1993.

28. McConnell TR, Laubach CA, Memon M. et al. Quality of life and self-efficacy in cardiac rehabilitation patients over 70 years of age following acute myocardial infarction and bypass revascularization surgery. Am J Geriatr Cardiol 2000; 9 (4): 210-218.

29. Fitzgerald ST, Becker DM, Celentano DD, et al. Return to work after percutaneous transluminal coronary angioplasty. Am J Cardiol 1989; 64 (18): 1108-12.

30. Balestroni G, Bosimini E, Centofanti P, et al. Stile di vita e aderenza ai trattamenti raccomandati dopo trapianto cardiaco. Ital Heart J Suppl 2002; 3 (6): 652-658.

31. Barlow JH, Williams B, Wright C. The Generalized SelfEfficacy Scale in people with arthritis. Arthritis Care Res 1996; 9 (3): 189-196.

32. Oldrige NB. Outcome assessment in cardiac rehabilitation. J Cardiopulmunary Rehabil 1997; 17: 179-194.

33. Roelands M, Van Oost P, Depoorter A, et al. A socialcognitive model to predict the use of assistive devices for mobility and self-care in elderly people. Gerontologist 2002; 42 (1): 39-50.

34. Rosenstock IM. Understanding and enhancing patient compliance with diabetic regimens. Diabetes Care 1985; 8 (6): 610-616.

35. Mc Gee HM, Hevey D, Horgan JH. Psychosocial outcome assessment for use in cardiac rehabilitation service evaluation: a 10 year systematic review. Social Science \& Medicine 1999; 48: 1373-1393.

36. Task Force per le Attività di Psicologia in Cardiologia Riabilitativa e Preventiva. Gruppo Italiano di cardiologia Preventiva e Riabilitativa. Linee Guida per le attività di psicologia in cardiologia riabilitativa e preventiva. Monaldi Arch Chest Dis 2003; 60 (3): 184-234.

37. Linden W. Psychological treatments in cardiac rehabilitation: review of rationales and outcomes. Journal of Psychosomatic Research 2000; 48: 443-454.

38. Marks R, Allegrante JP, Lorig K. A review and synthesis of research evidence for self-efficacy-enhancing interventions for reducing chronic disability: implications for health education practice (Part I). Health Promotion Practice 2005, 6 (1): 37-43.

\section{AKNOWLEDGEMENTS}

The authors thank Prof. Ralf Schwarzer for his suggestions. 